\title{
Study of spectrum of cardiac disease complicating pregnancy and the maternal and foetal outcome
}

\author{
Sudha R. ${ }^{1}$, Anjali R. ${ }^{2 *}$ \\ ${ }^{1}$ Department of Obstetrics and Gynecology, Mysore Medical College and Research Institute, Mysuru, Karnataka, India \\ ${ }^{2}$ Private Practitioner, Obstetrician and Gynecologist, Bengaluru, Karnataka, India
}

Received: 24 September 2019

Accepted: 31 October 2019

*Correspondence:

Dr. Anjali R,

E-mail: dr.anjaliramaswamy@gmail.com

Copyright: $\odot$ the author(s), publisher and licensee Medip Academy. This is an open-access article distributed under the terms of the Creative Commons Attribution Non-Commercial License, which permits unrestricted non-commercial use, distribution, and reproduction in any medium, provided the original work is properly cited.

\begin{abstract}
Background: Heart diseases are the most important non obstetrical causes of maternal deaths during pregnancy, accounting for almost $10 \%$ of maternal deaths. They complicate 1-3\% of all pregnancies.

Methods: The study was conducted at Cheluvamba Hospital from January 2015 till July 2016. All pregnant women with cardiac disease were included in the study. Pregnant women with cardiac disease were followed up during antenatal period, evaluated and maternal and foetal outcome was studied.

Results: Total number of deliveries in the one and half year study period was 18,803 cases and the total number of women with cardiac disease was 90 . Most of the subjects belonged to NYHA grade I and II (95.5\%), whereas NYHA grade III and IV constituted only $4.4 \%$ of cases. Rheumatic heart disease was the principal cardiac lesion (62.22\%) among the pregnancies, while congenital heart disease $(33.33 \%)$ was the second most common cause. $16.7 \%$ had cardiac complications and there were 2(2.22\%) maternal mortality. $91.86 \%$ were live births with $5.88 \%$ IUDs and 2.35\% neonatal deaths. $15.29 \%$ of the babies were Preterm, $8.14 \%$ were IUGR babies and $2.35 \%$ had congenital anomalies. It was noted NYHA grade III/IV cases had more preterm babies compared to NYHA grade I/II. NICU admissions were also more with NYHA grade III/IV.

Conclusions: The results suggest the need for pre-pregnancy counselling, early diagnosis, correction of cardiac lesions where indicated, close surveillance during pregnancy and a team approach comprising of obstetricians, cardiologists, neonatologists and nursing personnel for a successful pregnancy outcome.
\end{abstract}

Keywords: Cardiac disease, Coronary heart disease, Fetal outcome, New York heart association, Outcome, Pregnancy, Rheumatic heart disease

\section{INTRODUCTION}

Heart diseases are the most important non obstetrical causes of maternal deaths during pregnancy, accounting for almost $10 \%$ of maternal deaths. They complicate 1 $3 \%$ of all pregnancies with congenital defects in $70-80 \%$ of the cases. ${ }^{1}$ In developing countries like Pakistan, rheumatic heart disease (RHD) still accounts for the majority of cases and mitral stenosis is the most frequently observed valvular lesion. Recent advances in paediatric cardiology and cardiac surgery have enabled more than $85 \%$ of patients with congenital heart disease to survive to adulthood. Half of these patients are women, the majority of them of childbearing age. Most interventions, however are not curative, about half of the women with congenital heart disease face the prospect of further surgery, arrhythmia, heart failure, and-if managed inappropriately premature death. The additional burden of pregnancy represents a new challenge for this growing number of patients with heart disease. ${ }^{2}$ 
In the past few decades, rheumatic fever has decreased drastically in developed countries. Nevertheless, rheumatic fever remains problematic in the developing countries. ${ }^{3}$

The keys to successful diagnosis and management of incipient disease are: a high index of suspicion, particularly in women with known risk factors for cardiovascular disease and intensive monitoring during labour and delivery. Management of pregnant women with pre-existing cardiac problems should be undertaken by multidisciplinary teams in tertiary centres. In women with pre-existing cardiac disease wishing to proceed to term, cardiac status must be optimized pre-operatively and preferably a planned elective delivery should be scheduled. ${ }^{4}$

Foetal outcome depends on the degree of maternal wellbeing. Foetal mortality is not exceptionally high in patients with New York Heart Association (NYHA) class I and II, however if there is associated pulmonary hypertension there is a risk of abortions, intrauterine growth retardation, preterm delivery and early neonatal death. ${ }^{5}$

The present study was undertaken to study the current maternal and foetal outcome in patients with heart disease.

\section{METHODS}

The study was conducted at Cheluvamba Hospital from January 2015 till July 2016 at the Department of Obstetrics and Gynaecology. All pregnant women with cardiac disease were included in the study. Pregnant women with cardiac disease were followed up during antenatal period, evaluated and maternal and foetal outcome was studied.

Data was collected in a pre-designed proforma by taking the important variables for the objectives of the study. All cases of cardiac disease in the study period were included in the study and appropriate statistical methods were employed to tabulate the results.

Inclusion criteria for the study included both booked and unbooked pregnant women who were diagnosed to have cardiac disease. Pregnant women who were incidentally diagnosed to have cardiac disease and those who developed cardiac disease in peri-partum period were also included in the study.

Routine antenatal investigations like haemoglobin, urine microscopy, VDRL, blood grouping and Rh typing, HIV in ICTC centre, GCT and HbsAg were carried out and recorded. Apart from routine investigation, special investigations which aided in diagnosis and stratification of risk index were also carried out which include, chest $\mathrm{X}$-ray, electrocardiogram and echocardiography.
Ethical clearance was obtained from the ethical committee of our institution to carry out the present study.

\section{RESULTS}

Total number of deliveries in the one and half year study period was 18,803 cases and the total number of women with cardiac disease was 90 , giving a prevalence of $0.4 \%$.

Table 1: Distribution as per NYHA grading.

\begin{tabular}{|lll|}
\hline Grade & Number & Percentage \\
\hline 1 & 73 & $81.1 \%$ \\
\hline 2 & 13 & $14.4 \%$ \\
\hline 3 & 2 & $2.2 \%$ \\
\hline 4 & 2 & $2.2 \%$ \\
\hline
\end{tabular}

The pregnant women included in the study were assigned a baseline NYHA grading of I, II, III or IV depending on the severity of underlying cardiac disease. Most of the subjects belonged to NYHA grade I - $81.1 \%$. The NYHA grading distribution is depicted in Table 1.

Table 2: Types of maternal heart disease.

\begin{tabular}{|lll|}
\hline & Number & Percentage \\
\hline CHD & 49 & $31.11 \%+2.22 \%=33.33 \%$ \\
\hline RHD & 28 & $54.44 \%+7.78 \%=62.22 \%$ \\
\hline Others & 13 & $14.44 \%$ \\
\hline
\end{tabular}

The above table (Table 2) shows underlying cardiac conditions among the pregnant women included in this study. Rheumatic heart disease was the principal cardiac lesion - $62.22 \%$ among the pregnancies with cardiac disease, while Congenital heart disease $(33.33 \%)$ was the second most common cause.

Table 3: Distribution of cardiac complication.

\begin{tabular}{|lll|}
\hline & Number & Percentage \\
\hline Arrythmia & 2 & $2.22 \%$ \\
\hline CCF & 9 & $10 \%$ \\
\hline Infective endocarditis & 1 & $1.11 \%$ \\
\hline Pulmonary oedema & 1 & $1.11 \%$ \\
\hline Pulmonary embolism & 1 & $1.11 \%$ \\
\hline Sepsis & 1 & $1.11 \%$ \\
\hline CVA & - & - \\
\hline Cardiomyopathy & - & - \\
\hline
\end{tabular}

Table 4: Maternal outcome.

\begin{tabular}{|lll|}
\hline & Number & Percentage \\
\hline Uneventful & 75 & $83.3 \%$ \\
\hline ICU admission & 13 & $14.44 \%$ \\
\hline Death & 2 & $2.22 \%$ \\
\hline
\end{tabular}


In the present study cardiac complications were noted in $16.7 \%$ of pregnancies which are shown above. Among the cardiac complications, CCF $(10 \%)$ was the most common complication followed by arrhythmias $(2.22 \%)$ (Table 3). Two maternal deaths were documented (Table 4).

Table 5: Perinatal outcome $(\mathrm{N}=86)$.

\begin{tabular}{|lll|}
\hline & Number & Percentage \\
\hline Live births & 79 & $91.86 \%$ \\
\hline IUD & 5 & $5.88 \%$ \\
\hline Neonatal death & 2 & $2.35 \%$ \\
\hline Preterm & 13 & $15.29 \%$ \\
\hline IUGR & 7 & $8.14 \%$ \\
\hline Congenital anomalies & 2 & $2.35 \%$ \\
\hline NICU admissions & 28 & $32.56 \%$ \\
\hline
\end{tabular}

Infective endocarditis prophylaxis was given routinely to all cases of cardiac disease in pregnancy.

In our present study, $91.86 \%$ were live births, whereas $5.88 \%$ were IUDs and $2.35 \%$ were neonatal deaths. $15.29 \%$ were preterm deliveries and $8.14 \%$ were IUGR babies. $2.35 \%$ had congenital anomalies (Table 5).

Table 6: Comparison of NYHA grading and fetal complications - comparison.

\begin{tabular}{|lllll|}
\hline \multicolumn{2}{|c|}{ Bhatla et al } & \multicolumn{2}{l|}{ Present study } \\
\hline & NYHA & NYHA & NYHA & NYHA \\
& I/II & III/IV & I/II & III/IV \\
\hline Preterm & $20.5 \%$ & $30.95 \%$ & $13.95 \%$ & $25 \%$ \\
\hline NICU admissions & & $34.88 \%$ & $50 \%$ \\
\hline
\end{tabular}

On comparing the foetal outcome between NYHA I/II Vs NYHA III/IV, it was noted that preterm births as well as NICU admission were more in the NYHA grade III/IV group (Table 6).

\section{DISCUSSION}

The prevalence of cardiac diseases in pregnancy ranges from $1-3 \% .^{6}$ The total number of deliveries in our hospital during the study period was 18,803 deliveries over 18 months. In the present study the prevalence of cardiac disease was found to be $0.4 \%$, which is comparable to the study by Samuel et al $(0.9 \%)$ and Farhana et al $(0.98 \%){ }^{7,8}$ The other studies had slightly higher prevalence.

In our series $81 \%$ of cases were NYHA grade I, which is slightly higher than the results of other studies - Datta et al $(52.65 \%)$, Vaibhav et al $(30 \%)$ and Farhana et al $(70.9 \%) .{ }^{9-11}$ it implies that more number of patients have seeked health services earlier and treatment was instituted before the patient could further decompensate.
Only $4.4 \%$ cases were belonging to NYHA grade III/IV, in contrast to the results of other studies i.e., Mahesh et al (13.6\%), Vaibhav et al (21.66\%), Farhana et al (13.64\%) and Datta

Table 7: Distribution of cardiac complication comparison et al $(19.79 \%) .^{9-12}$

\begin{tabular}{|lllll|}
\hline & & & & \\
& & & & \\
& & & &
\end{tabular}

The maternal and perinatal outcome was found to be good in patients with NYHA grade I and II. Thus, NYHA grading serves as a predictor of maternal and foetal outcome.

Table 8: Comparison of NYHA grading and maternal complications.

\begin{tabular}{|c|c|c|c|c|}
\hline & \multicolumn{2}{|c|}{ Bhatla et al } & \multicolumn{2}{|c|}{ Present study } \\
\hline & $\begin{array}{l}\text { NYHA } \\
\text { I/II }\end{array}$ & $\begin{array}{l}\text { NYHA } \\
\text { III/IV }\end{array}$ & $\begin{array}{l}\text { NYHA } \\
\text { I/II }\end{array}$ & $\begin{array}{l}\text { NYHA } \\
\text { III/IV }\end{array}$ \\
\hline $\begin{array}{l}\text { Cardiac } \\
\text { complications }\end{array}$ & $23.03 \%$ & $57.14 \%$ & $16.27 \%$ & $50 \%$ \\
\hline LSCS & $13.86 \%$ & $46.34 \%$ & $22 \%$ & $50 \%$ \\
\hline $\begin{array}{l}\text { Post-partum } \\
\text { complications }\end{array}$ & $13.9 \%$ & $11.9 \%$ & $5.81 \%$ & $25 \%$ \\
\hline
\end{tabular}

A total of $54.44 \%$ of cases had RHD, whereas 7 cases (7.78\%) had MVP along with RHD. Total number of cases with RHD was $62.22 \%$, which is comparable with the results from other studies, Samuel et al (64\%), Pratibha et al $(60.92 \%)$ and Farhana et al $(66 \%) .{ }^{7,11,13}$ $33.33 \%$ of them had CHD which was comparable with the other studies and the rest had other cardiac lesions.

The incidence of RHD in developed countries has been greatly reduced by widespread use of antibiotics effective against the streptocccal infections. Higher number of RHD cases indirectly indicates inadequate treatment of streptococcal infections in childhood and adolescence. ${ }^{8}$

Rheumatic heart disease is the predominant cardiac disease in developing countries while congenital heart disease is the most common cause in developed 
countries. ${ }^{14}$ Nevertheless the incidence of congenital heart disease in developing countries is on the rise. Improving the socioeconomic conditions and access to medical care has resulted in decreasing trend of incidence of Rheumatic heart disease in developing countries.

The ratio of RHD: CHD in this study is $1.87: 1$, which is similar to the study by Pratibha et al $(1.91: 1) .^{13}$

The overall incidence of cardiac complications in this study was $16.7 \%$ which was similar to study by Samuel et al and Farhana et al, while Bhatla et al, had slightly higher rate of $29.95 \%$. $^{7,11,15}$

It was noted that complications were more common among NYHA grade III/IV. This implies that NHYA grade affects the maternal outcome.

In our study, 15 cases $(16.67 \%)$ landed up with cardiac complications and were admitted in our SICU. $10 \%$ of these cases had congestive cardiac failure, which was comparable to the results as obtained by study by Datta et al $(14 \%) .{ }^{9}$ other complications encountered in our study were arrythmia, infective endocarditis, pulmonary oedema, pulmonary embolism and sepsis (Table 7).

In this study $10 \%$ cases went into congestive cardiac failure. It is thought that this is caused by the increased venous return due to relief of inferior vena cava compression. ${ }^{16}$ These patients were managed successfully with medical therapy alone, including intravenous frusemide, morphine and oxygen inhalation. Thus, close monitoring throughout labour and in the early postpartum period is important to minimize and effectively treat complications, especially in patients with valvular lesions. ${ }^{15}$

Of the 90 cases, $83.33 \%$ of cases delivered uneventfully whereas $13 \%$ got admitted to ICU, recovered and were discharged. $2.22 \%$ of the cases died in this study.

When maternal complications were compared between two groups - NYHA I/II Vs, NYHA III/IV, it was noted that cardiac complications, LSCS rates and post-partum complications were all higher in NYHA grade III/IV group. All 3 parameters of the NYHA grade III/IV group were comparable to results of a study by Bhatla et al (Table 8). ${ }^{15}$

There were 2 maternal deaths in our study accounting to $2.22 \%$. One patient was a booked case elsewhere, who got admitted as NYHA grade III with pancytopenia, preterm labour with IUD. Patient underwent repeat LSCS but later developed post-partum psychosis along with wound gaping. She was diagnosed as a case of RHD with post-partum cardiomyopathy and later succumbed to the same.

The other patient was a multipara with RHD, NYHA grade III, who was on penidure, fruesemide, spironolactone and beta-blockers. She delivered an alive baby by forceps delivery. She later developed sepsis and succumbed to the same. Despite supportive therapy and maximum cardiac support, these patients could not be saved.

The rate is comparable to the results of the study by Farhana et al (2\%) and Vaibhav et al $(2.8 \%){ }^{10,12}$

The percentage of live births in our study was $91.86 \%$, which is comparable to the result obtained by Saman et al $(86 \%){ }^{8}$ Percentage of IUD - $5.88 \%$, neonatal death $2.35 \%$, preterm births - $15.29 \%$, congenital anomalies $2.35 \%$ and NICU admissions - $32.56 \%$.

There are several possible reasons for the increased rate of neonatal complications in pregnant women with heart disease. The relationship between maternal cyanosis and foetal growth has been well defined; maternal oxygen saturation is inversely related to birth weight and foetal mortality. ${ }^{17,18}$ The effect of functional class and left heart obstruction on preterm delivery, foetal death, and growth retardation is likely mediated by uteroplacental insufficiency. Indeed, foetalcardiac contractility and output are adversely affected by hypoxic acidemia resulting from uteroplacental insufficiency. ${ }^{19,20}$

Postulated reasons for the increased incidence of IUGR or prematurity include hemodynamic compromise secondary to valvular stenosis, maternal arrhythmias and cardioactive drugs including diuretics, digitalis and beta blockers, which have been associated with impairment of uterine blood flow. ${ }^{21-23}$

On comparing the foetal outcome between NYHA I/II Vs NYHA III/IV, it was noted that preterm births as well as NICU admission were more in the NYHA grade III/IV group. The results were comparable to the results obtained by Bhatla et al. ${ }^{15}$

This implies that NYHA grading is an indicator foetal outcome. In our study, 32 babies got admitted to the NICU. The most common indications for NICU admissions were low birth weight (31.25\%) and meconium aspiration syndrome $(31.25 \%)$.

The low incidence of maternal and neonatal mortality at this centre in this study is probably due to close monitoring of our patients during pregnancy by obstetricians and cardiologists and immediate intensive neonatal care.

\section{CONCLUSION}

Cardiac disease is an important cause of mortality during pregnancy and can result in significant morbidity. In the present study,

- The course of pregnancy as well as maternal and foetal mortality and morbidity are dependent on both 
the type of underlying cardiac disease and the NYHA functional grading

- The results suggest the need for pre-pregnancy counselling, early diagnosis, correction of cardiac lesions where indicated, close surveillance during pregnancy and a team approach comprising of obstetricians, cardiologists, neonatologists and nursing personnel for a successful pregnancy outcome

- RHD is still the leading cause of maternal heart disease during pregnancy in developing countries, while the incidence of congenital heart disease is on the rise. The ratio of RHD: CHD is now reversing as a result of reduction in cases of RHD owing to the improved socio economic status, education and access to health care.

Funding: No funding sources

Conflict of interest: None declared

Ethical approval: The study was approved by the Institutional Ethics Committee

\section{REFERENCES}

1. Montoya ME, Karnath BM, Ahmad M. Endocarditis during pregnancy. South Med J. 2003;96:1156-7.

2. James AH, Jamison MG, Biswas MS, Brancazio LR, Swamy GK, Myers ER. Acute myocardial infarction in pregnancy. Circulation. 2006;113:1-8.

3. Elkayan U. Pregnancy and cardiovascular heart disease, in Zipes D, Libby P, Bonow R, Braunwald E (eds): Braunwald's Heart Disease, 7th edition. Elsevier Saunders, Philadelphia; 1985:1965-1985.

4. Avila WS, Rossi EG, Ramires JA, Grinberg M, Bortolotto MR, Zugaib M, et al. Pregnancy in patients with heart disease. Experience with 1000 cases. Clin Cardiol. 2003;26:135-42.

5. Presbitero P, Somerville J, Stone R, Aruta E, Spiegelhatter D, Rabajdi F. Pregnancy in cyanotic congenital heart disease. Outcome of mother and fetes. Circulation. 1994;89:2673-6.

6. Khairy P, Ouyang DW, Fernandes SM. Pregnancy outcome in women with congenital heart disease. Circulation. 2006;113:517-24.

7. Siu SC, Sermer M, Colman JM, Alvarez AN, Mercier LA, Morton BC, et al. Prospective multicenter study of pregnancy outcomes in women with heart disease. Circulation. 2001;104(5):515-21.

8. Puri S, Bharti A, Puri S, Mohan B, Bindal V, Verma S. Maternal heart disease and pregnancy outcomes. JK Sci. 2013;15(1):7.

9. Chaitali DR, Kumar SB. Outcome of pregnancy after cardiac surgery: A comparative analysis. J Obstet Gynecol Ind. 2004;54(6):556-60.
10. Patil V, Bhingare P, Murthy B. Evaluation of maternal and foetal outcome of pregnancy with heart disease with special reference to surgically corrected heart diseases. Int J Sci Res Pub. 2014:184.

11. Farhana A, Asghar F, Kokab H. Evaluation and outcome of pregnancy complicated by heart disease. J Pak Med Assoc 2005;55:416-9.

12. Koregol M, Mahale N, Nayak R, Bhandary A. Maternal and perinatal outcomes of pregnancies complicated by cardiac disease. J Turkish - German Gynecol Assoc. 2009;10:30-4.

13. Pratibha D, Srilakshmi Y, Kiranmai, Swathi D. Pregnancy in cases of congenital heart disease. J Obstet Gynecol India. 2010;60(1):33-7.

14. Siu SC, Sermer M, Colman JM, Alvarez AN, Mercier LA, Morton BC, et al. Prospective multicenter study of pregnancy outcomes in women with heart disease. Circulation. 2001;104(5):515-21.

15. Bhatla N, Lal S, Behera G, Kriplani A, Mittal S, Agarwal N, et al. Cardiac disease in pregnancy. International J Gynecol Obstet. 2003;82(2):153-9.

16. Uebing A, Steer PJ, Yentis SM. Pregnancy and congenital heart disease. BMJ. 2006;1-6.

17. Presbitero P, Somerville J, Stone S. Pregnancy in cyanotic congenital heart disease: outcome of mother and fetes. Circulation. 1994;89:2673-6.

18. Whittemore R. Congenital heart disease: its impact on pregnancy. Hosp Pract. 1983;18:65-74.

19. Rizzo G, Arduini D. Fetal cardiac function in intrauterine growth retardation. Am J Obstet Gynecol. 1991;165:876-82.

20. Lewinsky RM, Szwarc RS, Benson LN. The effects of hypoxic acidemia on left ventricular end-systolic elastance in foetal sheep. Pediatr Res. 1993;34:3843.

21. Hanania G, Thomas D, Michel PL, Garbarz E, Age C, Millaire A, et al. Pregnancy and prosthetic heart valves: a French cooperative retrospective study of 155 cases. Eur Heart J. 1994;15:1651-8.

22. Suri V, Sawhney H, Vasistha K, Renuka T, Grover A. Pregnancy following cardiac valve replacement surgery. Int J Gynecol Obstet. 1999;64:239-46.

23. Kasab SM, Sabag T, Al Zeibag M, Awaad M, Al Bitar I, Halim MA, et al. b-Adrenergic receptor blockade in the management of pregnant women with mitral stenosis. Am J Obstet Gynecol. 1990;163:37-40.

Cite this article as: Sudha R, Anjali R. Study of spectrum of cardiac disease complicating pregnancy and the maternal and foetal outcome. Int $\mathbf{J}$ Reprod Contracept Obstet Gynecol 2019;8:4803-7. 